\title{
Characteristics of successful alien plants
}

\author{
M. VAN KLEUNEN, W. DAWSON and N. MAUREL \\ Ecology, Department of Biology, University of Konstanz, Universitätsstrasse 10, Konstanz D-78457, Germany
}

\begin{abstract}
Herbert Baker arguably initiated the search for species characteristics determining alien plant invasion success, with his formulation of the 'ideal weed'. Today, a profusion of studies has tested a myriad of traits for their importance in explaining success of alien plants, but the multiple, not always appropriate, approaches used have led to some confusion and criticism. We argue that a greater understanding of the characteristics explaining alien plant success requires a refined approach that respects the multistage, multiscale nature of the invasion process. We present a schema of questions we can ask regarding the success of alien species, with the answering of one question in the schema being conditional on the answer of preceding questions (thus acknowledging the nested nature of invasion stages). For each question, we identify traits and attributes of species we believe are likely to be most important in explaining species success, and we make predictions as to how we expect successful aliens to differ from natives and from unsuccessful aliens in their characteristics. We organize the findings of empirical studies according to the questions in our schema that they have addressed, to assess the extent to which they support our predictions. We believe that research on plant traits of alien species has already told us a lot about why some alien species become successful after introduction. However, if we ask the right questions at the appropriate scale and use appropriate comparators, research on traits may tell us whether they are really important or not, and if so under which conditions.
\end{abstract}

Keywords: community assembly, ecological impact, functional traits, invasion biology, niche space, weeds

\section{Introduction}

Already in the Origin of Species, Darwin (1859) wrote that 'We cannot hope to explain such facts [distributional patterns and differences in speciation rates], until we can say why one species and not another becomes naturalized by man's agency in a foreign land'. So, a long-standing major objective in ecology and evolution is the identification of characteristics that contribute to the success of species outside their native range. Fifty years ago, in 1965, Herbert Baker published a list of 14 characteristics that an 'ideal weed' should possess (see notes below Table 1). This list was later slightly modified by Baker (1974) himself and by Young \& Evans (1976). While

Correspondence: M. van Kleunen, Fax: +49 7531 883430;

E mail: mark.vankleunen@uni konstanz.de
Baker's definition of a weed was not restricted to alien plants and focussed on plants in areas markedly disturbed by humans, most of the weeds studied by Baker were invasive alien plants. Therefore, it can be said that the search for characteristics that can explain success of alien plant species started half a century ago with the work of Herbert Baker.

The idea of the existence of invasiveness traits has received some scepticism (e.g. Thompson \& Davis 2011; Moles et al. 2012). Moreover, it is frequently emphasized though rarely tested that the contribution of traits to the success of alien plants has to be context dependent (e.g. Funk 2013; Kueffer et al. 2014). Notwithstanding this, there is considerable evidence that invasive alien species differ in certain traits from other, either native or alien, species, at least under certain contexts. For example, invasive aliens frequently grow fas- 
Table 1 Examples of traits that could potentially determine the answers to the questions in our schema (Fig. 1), predictions of how these traits may differ between successful and unsuccessful alien species and between successful alien and native species, and where Baker's ideal weed characteristics fit in. Note that the predictions of potential trait differences for a specific question are conditional on whether the species passed the preceding question(s) and that the list of traits is not exhaustive

\begin{tabular}{|c|c|c|c|c|c|}
\hline & Question & Examples of traits & $\begin{array}{l}\text { Successful } \\
\text { alien vs. } \\
\text { unsuccessful } \\
\text { alien }\end{array}$ & $\begin{array}{l}\text { Successful } \\
\text { alien vs. } \\
\text { native }\end{array}$ & $\begin{array}{l}\text { Baker's } \\
\text { ideal weed } \\
\text { characteristics }{ }^{\dagger}\end{array}$ \\
\hline \multirow[t]{7}{*}{ Region } & $\begin{array}{l}\text { A0 Has the } \\
\text { species been } \\
\text { picked up and } \\
\text { introduced? }\end{array}$ & $\begin{array}{l}\text { Ornamental pathway* } \\
\text { Ease of cultivation (germination characteristics, } \\
\text { growth rate, hardiness), attractiveness to } \\
\text { humans (size and colour of flowers, plant size) }\end{array}$ & $>$ & $>$ or & \\
\hline & \multirow[t]{2}{*}{$\begin{array}{l}\text { A1 Is the } \\
\text { appropriate } \\
\text { environment } \\
\text { present? }\end{array}$} & $\begin{array}{l}\text { Environmental optimum } \\
\text { Climatic optimum (photosynthetic pathway, } \\
\text { deciduousness, water use efficiency, flowering } \\
\text { phenology), nutrient use (ecological indicator } \\
\text { values, plastic root foraging, nutrient use } \\
\text { efficiency) }\end{array}$ & $<$ or $>$ & $(<,>\text { or })^{*}$ & \\
\hline & & $\begin{array}{l}\text { Environmental tolerance } \\
\text { Climatic range, niche width, adaptive } \\
\text { phenotypic plasticity, fitness homeostasis or } \\
\text { capability to capitalize on increased resources, } \\
\text { generalization of pollination system, } \\
\text { autonomous seed set }\end{array}$ & $>$ & $>$ or & $1,2,6,7,9$ \\
\hline & \multirow{4}{*}{$\begin{array}{l}\text { A2 Can it reach } \\
\text { the appropriate } \\
\text { sites? }\end{array}$} & $\begin{array}{l}\text { Dispersibility } \\
\text { Efficiency of dispersal vector }\end{array}$ & $>$ & $>$ or & \\
\hline & & $\begin{array}{l}\text { Long distance dispersal capacity, number } \\
\text { of propagules }\end{array}$ & $>$ & $>$ or & $5,8,9,10$ \\
\hline & & Propagule size, terminal velocity & $<$ & $<$ or & \\
\hline & & Seed bank longevity & $>$ & $>$ or & \\
\hline \multirow[t]{5}{*}{$\begin{array}{l}\text { Local } \\
\text { community }\end{array}$} & $\begin{array}{l}B 0 \text { Is its } \\
\text { required niche } \\
\text { space currently } \\
\text { occupied? }\end{array}$ & $\begin{array}{l}\text { Same traits as listed under question A1 and } \\
\text { traits related to resource capture (rooting } \\
\text { depth and architecture, canopy height and } \\
\text { architecture, growth form/functional guild, } \\
\text { phenology) }\end{array}$ & / & / & \\
\hline & \multirow{3}{*}{$\begin{array}{l}\text { B1 Can it } \\
\text { quickly occupy } \\
\text { a vacant niche? }\end{array}$} & $\begin{array}{l}\text { Dispersibility } \\
\text { Same traits listed under question A2 }\end{array}$ & \multicolumn{2}{|c|}{$\begin{array}{l}\text { See question A2 for } \\
\text { predictions }\end{array}$} & \\
\hline & & $\begin{array}{l}\text { Priority effect traits } \\
\text { Timing (time to germination, time to } \\
\text { resprouting, time to flowering) }\end{array}$ & $<$ & $<$ or & $2,4,13$ \\
\hline & & $\begin{array}{l}\text { Germination rate, vegetative spread, fecundity } \\
\text { (self compatibility, capacity for autonomous } \\
\text { self pollination, capacity to attract pollinators) }\end{array}$ & $>$ & $>$ or & $\begin{array}{l}1,3,5,6,7,8 \\
11,12\end{array}$ \\
\hline & $\begin{array}{l}\text { B2 Can it } \\
\text { replace native } \\
\text { occupants? }\end{array}$ & $\begin{array}{l}\text { Competitive ability (allelopathy, vegetative } \\
\text { growth, height), defence against generalist } \\
\text { herbivores and pathogens }\end{array}$ & $>$ & $>$ or & $11,13,14$ \\
\hline
\end{tabular}

*Predictions may differ for other introduction pathways.

†Baker's ideal weed characteristics (Baker 1965) are the following: (i) has no special environmental requirements for germination; (ii) has discontinuous germination (self controlled) and great longevity of seed; (iii) shows rapid seedling growth; (iv) spends only a short period of time in the vegetative condition before beginning to flower; (v) maintains a continuous seed production for as long as growing conditions permit; (vi) is self compatible, but not obligatorily self pollinated or apomictic; (vii) when cross pollinated, this can be achieved by a nonspecialized flower visitor or by wind; (viii) has very high seed output in favourable environmental circum stances; (ix) can produce some seed in a very wide range of environmental circumstances and has high tolerance of (and often plas ticity in face of) climatic and edaphic variation; (x) has special adaptation for both long distance and short distance dispersal; (xi) if a perennial, has vigorous vegetative reproduction; (xii) if a perennial, has brittleness at the lower nodes or of the rhizomes or root stocks; (xiii) if a perennial, shows an ability to regenerate from severed portions of the rootstock; and (xiv) has ability to compete by special means: rosette formation, choking growth, exocrine production (but no fouling of soil for itself) etc.

*If the environment has recently changed. 
ter, produce more seeds and capitalize more on extra nutrients than natives or noninvasive aliens (Pyšek \& Richardson 2007; van Kleunen et al. 2010a; Thompson \& Davis 2011; Dawson et al. 2012; Rejmánek et al. 2013). Therefore, although the importance of specific traits and trait values for the success of species has to be context dependent, the overall importance of traits cannot be denied. What we need to find out, however, is which traits are important at which invasion stage, at which spatial scale and in which environmental context.

In this essay, we provide an overview of issues that, we think, should be considered when testing for traits associated with success of alien plants. Some of those issues have already been raised before, but here we collect them in one place. Furthermore, we present a schema of questions that could guide research on which traits might be important at which stage of invasion and which species might be the right comparators to identify these traits. Because this schema of questions considers both the larger regional scale and the local-community scale, it also allows for more explicit consideration of context dependency in our search for invasion traits. We also review, though not exhaustively, studies that tested for traits associated with success of alien plants. Finally, we provide information on where the 14 ideal-weed characteristics of Baker (1965) fit within our schema of questions.

\section{Issues to be considered in the search for traits associated with success of alien plants}

An important issue to consider in our search for traits driving success of alien species is which species to compare (Hamilton et al. 2005; van Kleunen et al. 2010b). Most studies have compared invasive (i.e. highly successful) alien species to native species (see reviews by Pyšek \& Richardson 2007; van Kleunen et al. 2010a). However, this invasive-alien-vs-native comparison might not always provide us with the answers that we are seeking. First, one should consider that some of the native species are also successful (Rejmánek 1999; Muth \& Pigliucci 2006; van Kleunen et al. 2010b). Second, if one is interested in the question 'what determines success of alien species?', one should also include nonsuccessful or less successful alien species as comparators (Baker 1965; Rejmánek 1999; Muth \& Pigliucci 2006; van Kleunen et al. 2010b). Thus, although failed or less successful invasions are still understudied, they are key to gaining insights into the drivers of invasion success.

A second issue to consider is the different stages of the invasion process. Richardson et al. (2000) developed a widely applied framework to describe this process. In this introduction naturalization invasion framework, a species has to cross biogeographical, environmental and reproductive barriers to achieve the status of natural- ized alien (i.e. to establish a self-sustaining population), and dispersal and further environmental barriers to achieve the status of invasive alien (i.e. to spread in the landscape). For each of these transitions, one can ask which characteristics a species requires for success (Kolar \& Lodge 2001; Dietz \& Edwards 2006; Theoharides \& Dukes 2006). The few studies that empirically tested for traits associated with different transitions indeed found that different traits may be important at the different stages (van Kleunen et al. 2007; Dawson et al. 2009; Pyšek et al. 2009) or even that certain traits may have opposing effects at different transitions. For example, Moodley et al. (2013) found for the Proteaceae family that large seeds promoted naturalization but that small seeds promote invasion. Although the introduction naturalization invasion framework is very useful, it is only applicable at the larger regional scale (for which species can be classified as introduced, naturalized or invasive), which hampers the inclusion of the local-community context. In other words, it does not allow explicit consideration of the local-community scale; that is the scale at which plants interact with other plants and other trophic levels (e.g. micro-organisms, herbivores, pollinators).

The third issue to consider, and which is implicit in the above-mentioned stage-like nature of invasion, is spatial scale (Ackerly \& Cornwell 2007; Gurevitch et al. 2011), which is usually correlated with temporal scale. While establishment in a particular site is a local process (naturalization), spread of the species in the landscape, which is usually referred to as invasion (Richardson et al. 2000), is a regional process involving multiple local naturalization events. So, depending on whether one considers a local plant community or the flora of a larger region (e.g. a country or continent), one might expect different characteristics to be important for success. We therefore need to pitch our studies at the appropriate spatial scale according to the questions that we ask, and the stage of invasion that we are focussing on.

\section{A schema of questions}

Here, we develop a set of questions in a decision-tree framework that considers the different scales at which potentially important processes operate (Fig. 1). This is based on the idea that the barriers to invasion can be viewed as filters, similar to the ones considered in studies on the assembly of native communities (Belyea \& Lancaster 1999; Shea \& Chesson 2002). The first three questions in our schema apply to larger (regional) scales, and the last three questions apply to the localcommunity scale. The answers to these questions determine whether an alien species can locally establish, and ultimately, this determines whether it can establish and spread (i.e. invasion) at the regional scale. After each 


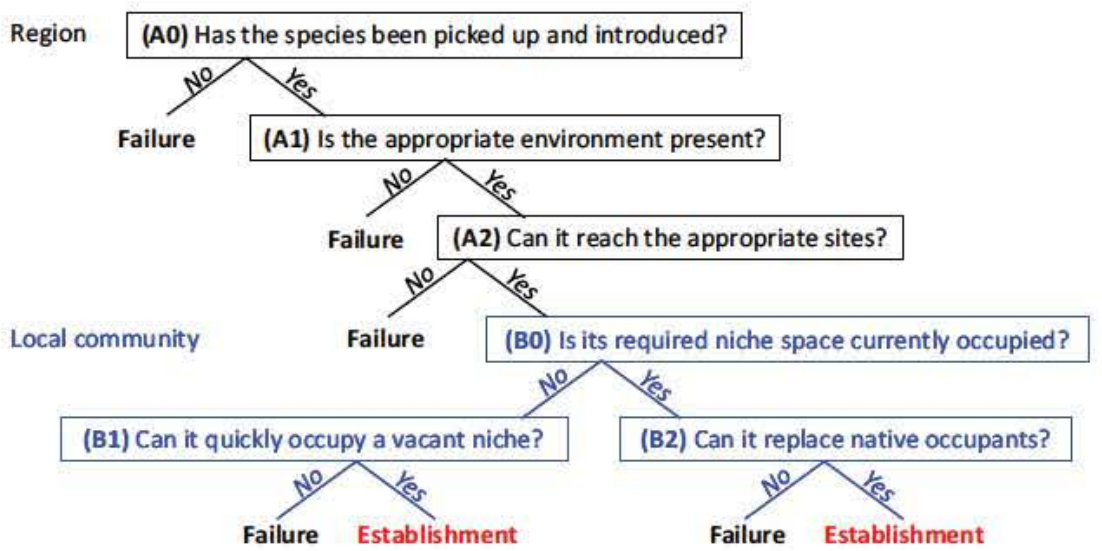

Fig. 1 Schema of questions that should guide research to find out which, if any, species traits are associated with the success of alien species, and at which stage of the invasion process. Questions A0 A2 apply to larger spatial scales, and questions B0 B2 apply to local plant communities. In Table 1, we list species traits that we think could determine the answers to these questions. In principle, there could also be a line connecting the results from question B1 to question B2. For example, if a species failed to quickly occupy a vacant niche before another species does, question B2 becomes relevant. Furthermore, if a species can first establish in a vacant niche and has a wider fundamental niche, it may replace occupants of the adjacent niche space (question B2).

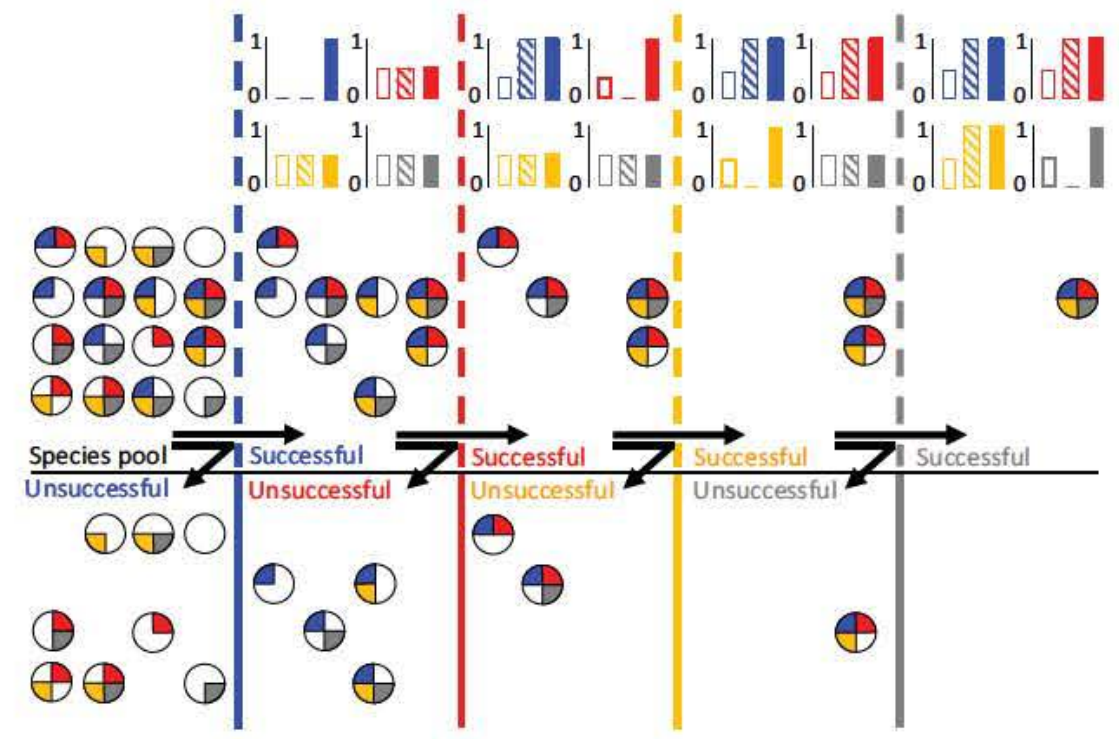

Fig. 2 Different characteristics might determine whether a species will or will not successfully pass each of the subsequent filters (questions), and consequently, the choice of the optimal comparator group for the successful species. In this example, each species (circle) can have four characteristics indicated by the four different colours, and the state of these characteristics determines whether a species can pass the filters of the same colours. For example, only species that possess the blue colour can pass the blue filter. The bar diagrams indicate the proportion of species that possess the particular colour; solid bars: species that successfully passed the respec tive filter, hatched bars: species that did not successfully pass the respective filter but successfully passed the preceding one(s), open bars: all the species from the initial species pool that did not pass the respective filter and also not the preceding ones. The difference in the proportion of species with each colour among successful species and unsuccessful species depends on the filter at which the colour is important and whether one also includes the unsuccessful species that failed already at one of the preceding filters.

question in this schema, fewer and fewer species from the introduced species pool remain with the potential to establish a local population (Fig. 2). Therefore, the comparators that are used to assess which traits are associated with each question in the schema should ideally come from the pool of species that did not fail already at a preceding question (Fig. 2).
Our schema of questions is not a risk assessment scheme (e.g. Daehler et al. 2004; Leung et al. 2012) or a classification/regression tree that predicts invasiveness based on certain characteristics or extrinsic factors (e.g. Reichard \& Hamilton 1997; Widrlechner et al. 2004; Caley \& Kuhnert 2006). Instead, our tree organizes questions that should provide guidance on which traits 
may be important at which stage and how we can test this. The answers to these questions will be partly determined by several factors other than species characteristics per se, such as environmental conditions and time since and frequency of introduction. However, even if a species has been introduced very early and very frequently, it is unlikely to establish when its trait values are not suitable for the environment in the region of introduction. In other words, the potential to pass through a certain filter should ultimately be determined by the characteristics of the species, unless all species are ecologically equivalent. Below we make, for each question, predictions of differences we would expect in species characteristics between successful alien and unsuccessful alien species, and between successful alien and native species, at local and regional scales (Table 1). We also evaluate some of the support, particularly from the more powerful multispecies studies (van Kleunen et al. 2014), that these predictions have received.

\section{Question A0: has the species been picked up and introduced?}

The first basic question to ask is whether a species has crossed, with man's help, the biogeographical barriers surrounding its native range (question A0 in Fig. 1 and Table 1). In other words, has the species been picked up and introduced? This simple question is in practice frequently difficult to answer, as for many non-naturalized species it is not known with certainty whether they have been introduced or not. However, already in Europe alone, more than 20000 taxa are commonly grown in private gardens (Cullen et al. 2011) and c. 80000 taxa in botanical gardens (Heywood \& Sharrock 2013). Therefore, given that the total number of known higher plant taxa is estimated to be c. 370000 (http://www. theplantlist.org/1.1/statistics/), a considerable proportion of all plant species has been intentionally introduced by humans outside their native range.

Even if most plant species may have been introduced into regions where they are not native, it is important to consider that some have been introduced earlier and more frequently than others. The basic question (question A0 in Fig. 1 and Table 1) then transforms into 'When and how frequently has the species been introduced elsewhere?' It is likely that introduced species, and among those, species introduced earlier and more frequently, are not a random subset of all species, but have certain characteristics that make them more likely to be introduced elsewhere. In other words, an introduction bias is likely to occur. Moreover, there are various introduction pathways (Hulme et al. 2008), and it is likely that each pathway promotes different plant characteristics. For example, plant species that have been introduced for ornamental purposes might have been selected for characteristics that make them attractive to humans and easy to cultivate (Chrobock et al. 2011). One might therefore expect that such introduced aliens germinate more easily, grow faster and have more attractive flowers compared to species not introduced and to most, but not necessarily all, of the native species (Table 1). For those ornamental alien species grown in outdoor gardens, however, one would expect their cold hardiness to be similar to the cold hardiness of the natives. So, depending on the introduction pathway, the trait and the comparator group, one might expect different outcomes for comparative studies on traits associated with introduction.

Many studies have addressed how different aspects of introduction history relate to current naturalization or invasion success of species (e.g. Lonsdale 1994; Knapp \& Kühn 2012). However, very few studies have addressed which traits are associated with a species' introduction history. The easiest species to study in this regard are ornamentals, as there are records of which species are used in international horticulture (e.g. https://www.rhs.org. $\mathrm{uk} /$ plants/) and of when and where some of them have been introduced (e.g. Goeze 1916). Two approaches have been used to shed light on the existence and magnitude of an introduction bias. First, the source-region approach (sensu Pyšek et al. 2004) tests which alien species have been introduced elsewhere and which ones not. van Kleunen et al. (2007) showed for a comprehensive data set of 1036 species of Iridaceae native to southern Africa that international horticultural usage was more likely for species with a larger native range, a lower maximal altitude in southern Africa and a greater height. Similarly, Pyšek et al. (2014) found that Central European species with a greater height and bigger propagules were more likely to be used in cultivation both in their native range and in North America. Second, the sink-region approach (sensu Pyšek et al. 2004) tests how alien species, irrespective of whether they are invasive or not, deviate from native species in the introduced region. Chrobock et al. (2011) compared germination characteristics between 47 introduced ornamental alien herbs and 42 native herbs in Switzerland. They found that the ornamental aliens, and particularly cultivars, germinated earlier and more successfully than the natives. This indicates that there might indeed be an introduction bias as well as effects of human-mediated selection with regard to the characteristics of introduced aliens, and this might affect the comparisons at the subsequent invasion stages.

\section{Question A1: is the appropriate environment present?}

Once a species has been introduced to a new region, it can only establish naturalized populations if there is an environment where the species is physiologically able to grow 
and reproduce. The second question in our schema is thus whether the appropriate environment is present in the region of introduction (question A1 in Fig. 1 and Table 1). The answer to this question will obviously depend on the region, and the environmental requirements, preferences and tolerances of the introduced alien species (e.g. the degree of climatic niche match between the introduced and native range; Petitpierre et al. 2012), as well as on traits that determine whether it can reproduce (e.g. pollen vector, flowering phenology and breeding system; see question B1). In other words, the answer to this question will be highly context dependent.

Characteristics of species associated with their climatic optima such as photosynthetic pathway, water-use efficiency and deciduousness and with nutrient requirements such as ecological indicator values (e.g. Ellenberg values for nitrogen), plastic root foraging and nutrient-use efficiency may be important. The optimal trait values will obviously depend on the environmental context. However, on average, species with a wide environmental tolerance, and thus a potentially broad niche, should be more likely to encounter suitable growing conditions. A wide environmental tolerance, that is the maintenance of high values of fitness-related traits across an environmental gradient, is frequently assumed to be achieved through high levels of adaptive phenotypic plasticity in functional traits (i.e. the 'general-purpose genotype' of Baker 1965). However, it is still rarely assessed whether trait plasticity in response to the environment is really adaptive (van Kleunen \& Fischer 2005) or whether homeostasis in certain traits contributes to environmental tolerance. It is therefore perhaps not surprising that recent meta-analyses on the role of plasticity in plant invasions were not very conclusive (Davidson et al. 2011; Palacio-López \& Gianoli 2011).

As most native species also successfully grow and reproduce in regions invaded by aliens, successful alien species should have environmental requirements, and thus characteristics, similar to those of most native species in the region. However, if the alien species have taken advantage of environmental conditions not exploited by natives or of novel environmental conditions (e.g. due to land-use change, atmospheric nutrient deposition or climate change) to which most of the native species may not have adapted yet, the successful aliens could differ from most of the natives. This has been demonstrated in Hawai'i, where distinct leaf traits allow some invasives to occupy novel, human-created biogeochemical niches not exploited by native species (Peñuelas et al. 2010). Furthermore, this could also underlie the finding that invasive alien species in the Iberian Peninsula have higher photosynthetic nitrogenuse efficiencies than native species (Godoy et al. 2012). Therefore, we predict that in regions that have recently undergone environmental change, there are stronger differences between successful aliens and natives.

Among the introduced alien species, those without the characteristics allowing growth and reproduction in any of the environments in a region will not establish. Therefore, one would expect clear differences between successful and unsuccessful alien species. In line with this, a recent study by Dostál et al. (2013) found that among 264 Central European plants, the ones from more productive habitats are more invasive at a global scale. In a similar vein, Dawson et al. (2012) found in a study on 18 alien species in Switzerland that the invasive ones capitalize more strongly on fertilizer addition than the noninvasive ones. These results suggest that many successful aliens have taken advantage of the global increase in atmospheric nitrogen deposition (Galloway et al. 2008). However, for other traits that determine the environmental optimum of a species, the direction of the trait-value differences between successful and unsuccessful alien species will be context dependent (i.e. region specific). For example, species from either Arctic or tropical regions will most likely not find suitable environments in temperate regions. This means that the successful species do not necessarily have universally higher or lower trait values than the average unsuccessful ones, but that their values might be in between the values of unsuccessful species. To the best of our knowledge, no study has yet tested for unimodal (or inverse unimodal) relations between establishment success of aliens and their trait values.

On the other hand, for traits that determine environmental tolerance (i.e. niche width), one would expect on average higher values in successful than in unsuccessful species, as tolerance increases the likelihood that the fundamental niche of a species overlaps with the available niche space in a region. Indeed, the study by Dostál et al. (2013) on 264 Central European plants found that species primarily occurring in nutrient-poor habitats but also found in more productive habitats (i.e. species that have a wide productivity niche) are globally more invasive. This finding supports the idea that environmental tolerance increases the establishment success of introduced alien species.

\section{Question A2: can it reach the appropriate sites?}

When a suitable environment is present in a region, the introduced alien species can obviously only establish if it manages to get to some of the suitable sites. Moreover, to spread rapidly in the landscape, the species needs to reach many suitable sites. The third question in our schema is therefore whether the introduced alien species can reach the appropriate sites, given that there 
are such sites (question A2 in Fig. 1 and Table 1). The likelihood that a species will reach a suitable site will, in addition to extrinsic factors such as the frequency and spatial configuration of these sites, depend upon the mobility of the species. Therefore, dispersal-related traits, such as the dispersal vector and the number, weight and terminal velocity of propagules (e.g. seeds or fruits), are likely to be important.

Some unsuccessful aliens may also be very mobile, but their failure might be due to the lack of suitable environments in the region (i.e. they might have failed already at question A1; also see Fig. 2). Therefore, successful alien species should have higher values of traits promoting dispersibility than unsuccessful alien species that could potentially live in the same sites. Because species with smaller, and frequently more seeds (Moles \& Westoby 2006), may disperse further, many studies have compared seed size between more and less successful aliens. Rejmánek \& Richardson (1996) found that among $24 \mathrm{Pi}$ nus species, the invasive ones indeed have smaller seeds than noninvasive ones. However, Castro-Díez et al. (2011) found that among 85 Australian Acacia species, the ones that have become invasive elsewhere do not differ in seed mass from the ones that failed to become invasive. On the other hand, Lake \& Leishman (2004) found that among 57 exotic species in urban bushland in Sydney, Australia, the invasive species tended to have heavier seeds than the noninvasive species. Results regarding seed size are thus variable, but given that seed size does not only affect dispersibility but also other ecological functions, the inconsistent results are not surprising. While small-seeded species may be better dispersed, once a site is reached, larger-seeded species may have an advantage through more stored resources and faster growth (Turnbull et al. 2008). The multiple ecological functions of seed size could thus result in species with intermediate seed sizes having the highest establishment success, but such a unimodal relationship has not yet been tested. Furthermore, the above-mentioned invasion studies may not have consistently defined unsuccessful species; some of them may have failed to reach suitable sites or failed to establish after dispersal.

Other studies have looked at traits other than seed size that are more directly related to dispersibility or at estimates of spread rate. For example, Bucharová \& van Kleunen (2009) found that seed-spread rate among 192 North American tree species is positively associated with their naturalization success in Europe, although such a relationship is absent among 86 North American shrubs. Moravcová et al. (2010) found that among 93 neophytes in the Czech Republic, the invasive ones have a lower seed terminal velocity (i.e. a higher capacity for wind dispersal) than noninvasive ones. Murray \& Phillips (2010) found that among 88 naturalized plants in southeastern Australia, invasive species invest more in seed dispersal appendages. So, overall, these results suggest that many successful alien species are better dispersers than nonsuccessful alien species.

Among native plant species, one would also expect that the ones with a high dispersibility are more successful than the ones with a low dispersibility. Consequently, if one would compare successful aliens with a mixture of successful and unsuccessful natives, the successful aliens should, on average, have higher values. However, if one would compare them to successful natives, such a difference should be absent. So, the choice of the native comparator group is also important. Daws et al. (2007) compared individual seed mass of 225 native and 33 invasive Asteraceae and of 74 native and 44 invasive Poaceae in California and found that the invasive species had on average higher values. These results suggest that invasives may have a lower dispersibility than related natives with potentially similar niche requirements. Possibly, seed size is not the main driver of dispersibility in these two families but has other important ecological functions. Moreover, one potential reason why studies may sometimes fail to find dispersal traits that explain spread rates of alien plants lies in the fact that they ignore long-distance dispersal events, which may be particularly important in fragmented landscapes, but are very unpredictable (Nathan 2006; Nathan et al. 2008).

When a species disperses, its seeds might end up in sites that are currently not suitable for establishment. Dispersal in time by means of the accumulation of a persistent soil seed bank could allow the species to wait for the right environmental conditions (Gioria et al. 2012). Moreover, even when the current environment is already suitable for establishment, a persistent soil seed bank can rescue populations that are small and vulnerable to demographic and environmental stochasticity. The latter is likely to be important in environments with strong, but spatio-temporally patchy, disturbance, which are frequently dominated by invasive aliens. Recently, Gioria et al. (2012) showed in a database study that the capacity to build up a persistent seed bank is more frequent among 32 invasive than among 39 naturalized and 92 casual species in the Czech Republic. However, the frequency of species with a persistent seed bank among the invasive aliens was similar to the frequency among 185 natives. This emphasizes that successful aliens frequently should differ from unsuccessful ones, but may be similar to natives.

\section{Question B0: is the required niche space currently occupied?}

Once the propagules of an introduced alien species have reached a potentially suitable site in the non-native 
region, the next question in our schema (question B0 in Fig. 1 and Table 1) is whether its niche space is already occupied or not. In both cases, population establishment might be possible, but this will depend, at least partly, on a different set of traits (questions B1 and B2 in Fig. 1 and Table 1). Because at large spatial scales both alien and native species have to pass the same environmental filters, the environmental requirements of both must match the range of environmental conditions that are locally available. Thus, the traits determining whether the required niche space in the local community is already occupied should be, in the first place, the same traits determining whether the suitable environment is present in a region (question $\mathrm{A} 1$ in Fig. 1; i.e. traits that determine the environmental optimum and traits that determine the environmental tolerance of a species). For these traits, the alien species should have trait values that fall within the range of those of the natives, but its environmental niche space could still be available if the alien species does not have an equivalent native species with similar trait values in the community. As the vacant niche space might be at any position within the overall environmental space, the successful alien does not necessarily differ from the average native species (Fig. 3). In other words, the difference between successful aliens and natives in the community will be context dependent. However, a successful alien should be more different from the most similar native species in that site than an alien that reached the site but did not establish it.

Even when the environmental requirements of the alien species overlap those of the native species in the local community, there could still be a vacant niche if the alien species has traits that are novel to the community and allow the species to access part of the environment to which the natives do not have access. Traits that might be important here are those that determine how species exploit their environment. While resource (i.e. light, water, nutrients) requirements are likely to overlap between the alien and native species in a community, species might still differ in traits involved in resource capture. This can be illustrated with nutrient acquisition. An experimental comparison between one invasive and two native annual species of the Mojave desert showed that the invasive had a greater root surface area and exploited deeper soils (DeFalco et al. 2003). In a nutrient-limited experimental system, Drenovsky et al. (2008) found that four invasive species allocated proportionately more root length to nutrient-rich microsites in the heterogeneous nutrient distribution treatment compared to the control with a homogeneous nutrient distribution, than four native species did. These studies at the community level are typically focused on one or a few species, but further investigation across multiple invasive species and multiple invaded communities should help to understand how fine-scale niche differentiation may promote the establishment of alien species in local plant communities.

\section{Question B1: can it quickly occupy a vacant niche?}

When propagules of the alien species have reached a suitable site, and the required niche space is not occupied yet by a native species, the next question is

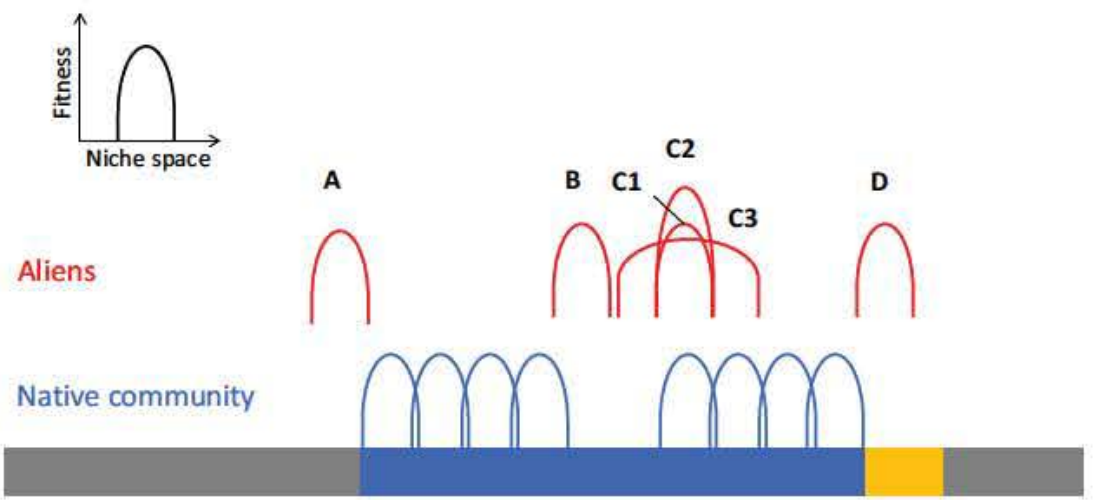

Fig. 3 Potential establishment of different alien species into a native community. The niche requirements of aliens A and D fall out side the current available environmental space (blue horizontal band) and have trait values that are either smaller or larger than those of the natives (and the successful aliens). However, if due to recent environmental change available environmental space is extended (orange horizontal band), alien D will be able to establish and will have trait values that differ from those of the natives. Aliens $\mathrm{B}$ and $\mathrm{C}$ both fall in the range of trait values shown by the natives and in this case, have values close to the average value of the native community. However, alien C $\left(\begin{array}{ll}1 & 3\end{array}\right)$ has the same environmental optimum as one of the native species, while alien $B$ is more dissimilar to the most similar native species. As a consequence, alien $\mathrm{B}$ will have the highest chance to establish. Alien $\mathrm{C}$ could only invade if it had trait values resulting in greater fitness (C2) than the native species with a similar niche optimum, allowing it to outcompete the native, or if it has a wider niche (C3), allowing it to occupy part of the vacant niche space. 
whether the alien species can quickly occupy the vacant niche before another newcomer does (question B1 in Fig. 1 and Table 1). First, traits that increase the influx of propagules to the site should be advantageous, as these would help to overcome Allee effects and stochastic effects. These would be the traits that increase dispersibility, mentioned under question A2. When the same number of propagules has arrived at a site, then other characteristics that contribute to priority effects (Morin 1999) should be advantageous. These are traits that (i) allow a species to occupy the available space earlier than other species (e.g. early germination, early sprouting) and that (ii) allow a species to grow there in large numbers (e.g. a high germination rate, production of numerous seeds, vegetative proliferation). Associated with the latter are traits that make a species less reliant on external factors that could delay its reproduction (self-compatibility, autonomous self-pollination). The successful alien species should differ in these traits from unsuccessful aliens and native species with similar niche requirements, but not necessarily when compared to native or unsuccessful alien species in general (Table 1).

There are indeed multiple empirical studies suggesting that traits contributing to priority effects are associated with success of alien species. van Kleunen \& Johnson (2007a) showed that among 60 South African Iridaceae, the ones that have become naturalized elsewhere germinated faster and more profusely. Recently, in a study on 28 grassland species, Wilsey et al. (2014) also showed that alien species germinated faster and more profusely than natives and that these aliens as a consequence had stronger priority effects on species sown later. Moravcová et al. (2010) found that among 93 neophytes in the Czech Republic, the invasive ones had a higher fecundity. Self-compatibility and autonomous seed set may contribute to fecundity and are indeed frequently associated with alien plant success (Rambuda \& Johnson 2004; van Kleunen \& Johnson 2007b; van Kleunen et al. 2008; Küster et al. 2008; Hao et al. 2011). This frequent finding is also in line with Baker's idea, published 10 years before his list of idealweed characteristics, that organisms capable of uniparental reproduction are more likely than obligate outcrossers to establish populations after long-distance dispersal (Baker 1955). So, overall, it seems that traits providing species with a priority-effect advantage are associated with success of alien plants.

\section{Question B2: can it replace native occupants?}

When the propagules of an alien species have reached a site that would in principle be suitable, the required niche space may already be occupied by a native species.
The question then is whether the alien species can replace (or coexist with) this native species (question B2 in Fig. 1 and Table 1). Therefore, introduced alien species with trait values that increase competitive ability

such as a tall stature, fast vegetative growth or the production of allelopathic chemicals might be more likely to establish. It should furthermore be advantageous for the alien species to have a higher resistance against generalist herbivores and pathogens than the native species that is occupying its niche, as this will also give the alien species a competitive advantage. The successful alien species should have higher values of these traits than the native species that it is replacing, but not necessarily when compared to the other native species in the community that do not use the same niche space (Fig. 2). Unsuccessful alien species with similar niche requirements should have lower values of these traits than the successful alien species. In other words, if alien species are to successfully outcompete and replace native species, they should have traits promoting a higher fitness compared to unsuccessful aliens and to natives, despite having similar niche-related traits (Fig. 3).

Although it is frequently implied that invasive alien plants outcompete native plants, relatively few studies have directly assessed the competitive ability of successful alien plants. Vilà \& Weiner (2004) concluded in a review that the effect of invasive species on native species is usually stronger than vice versa. However, in a large experiment with 12 invasive species in the Czech Republic, Dostál (2011) showed that the intensity of competition was not affected by whether the competing neighbour was a native or an invasive alien species. Furthermore, although allelopathy has been suggested to drive the success of several highly invasive species, such as Centaurea diffusa (Callaway \& Aschehoug 2000) and Alliaria petiolata (Prati \& Bossdorf 2004; Stinson et al. 2006), Dostál (2011) also found no evidence for the role of allelopathy in competitive interactions of the 12 invasive species in his study. However, he found that the best predictor of competitive intensity was plant size. Therefore, taller aliens might be more successful. On the other hand, other studies revealed mixed evidence for the role of stature. Bucharová \& van Kleunen (2009) found that naturalization success of North American trees in Europe was associated with maximum height, but that this was not the case for North American shrubs. Hamilton et al. (2005) did not find an association between plant height and invasiveness of alien species in Australia. Speek et al. (2011) found a correlation between plant height and regional frequency of alien plants, but not between plant height and local dominance, which is actually the most relevant spatial scale for this trait to be important for replacement of native species in invaded communities. This mixed 
evidence of plant height as an important trait promoting successful replacement of natives could be due to plant height increasing competitive ability only in certain communities and habitats, emphasizing again context dependency. Moreover, it could be that some of the tall unsuccessful aliens in these studies had failed at one of the earlier stages and therefore were not optimal comparators.

\section{Where do Baker's ideal-weed characteristics fit in the schema of questions?}

When devising the characteristics of an ideal weed (see notes below Table 1), Baker (1965) defined weeds as having 'populations [that] grow entirely or predominantly in situations markedly disturbed by man'. Because of this restriction to disturbed habitats, it is perhaps unsurprising that the majority of Baker's ideal-weed characteristics can be assigned to question B1 in our schema ('Can it quickly occupy a vacant niche?'; Fig. 1; Table 1). Characteristics of species that should be able to quickly occupy and increase in abundance in a vacant niche include the following ideal-weed characteristics (Table 1): no special germination requirements, rapid growth, an ability to produce seeds throughout the growing period and in high volumes in favourable environments, little or no dependence on (specialized) pollinators for seed production, and vegetative reproduction. Some characteristics might also act as priorityeffect traits, with invaders able to germinate (controlled seed germination), flower (short time to flowering) and establish (through vegetative propagation) earlier than native species when a vacant space arises.

Before a species is able to occupy a vacant niche in a local community, the local community should first be in an appropriate environment (question A1). However, a number of Baker's ideal-weed characteristics that could enable a vacant niche to be occupied would also result in greater environmental tolerance, therefore increasing the probability of an appropriate environment being present (no special germination requirements, self-controlled germination and seed longevity, self-compatibility/lack of dependence on pollinators being present, plant tolerance to and seed production under varying climatic and edaphic environments). But even if an appropriate environment is present, propagules must be able to disperse there (question A2) and to vacant niches in a community (question B1), which should be more likely for species with adaptations for short- and long-distance dispersal, another of Baker's ideal-weed characteristics. In addition, continuous seed production throughout the growing season, high seed production in favourable environments and an ability to produce seeds in multiple environments are characteristics that will increase the probability of seeds reaching suitable environments at larger scales and vacant niches at smaller scales.

Given Baker's focus on weeds in ruderal and agricultural habitats, it is not surprising that relatively few of the ideal-weed characteristics would be implicated in replacement of native species (question B2); competition is presumably (and at least initially) of low importance in such open habitats. Baker does, however, suggest that an ideal weed would have an ability to compete by 'special means' including direct competition via allelopathic effects on natives. 'Vigorous vegetation reproduction' in an invader might also result in native species being outcompeted and replaced. However, Baker's concentration on ruderal and agricultural weeds likely means that the ideal-weed characteristics are only one possible syndrome of successful alien species.

\section{Discussion}

The intensive search for traits explaining success of alien plant species and invasions has not yet led to the identification of a universal syndrome of invasion traits. This may partly be because invasions are complex processes with multiple stages, occurring at different spatial and temporal scales, and these complexities have not always been considered in studies searching for invasiveness traits. Thus, the inability to find a universal suite of traits that consistently differ between successful alien and unsuccessful alien or native species could be because there are multiple successful suites of traits, depending on context. This does not mean that traits are unimportant; however, we need to work out which sets of traits are most important under different contexts.

Our schema of questions (Fig. 1) organizes a series of questions at regional and community scales that could guide research on traits associated with success of alien plants. Based on this schema, we have made predictions regarding how we expect successful aliens, unsuccessful aliens and natives to differ in their traits, and which traits are most relevant for each question asked (Table 1). When testing a hypothesis based on this schema of questions, it is important to consider that the group of species to which each question applies is conditional upon the preceding questions (Fig. 2). This means that if one wants to test, for example, whether successful alien species are more mobile than unsuccessful alien species, one should ideally select successful and unsuccessful aliens that all have been introduced and all have suitable environments in the region (Fig. 2). The reason is that an unsuccessful alien that did not pass one of the earlier questions, for example because its climatic requirements are not fulfilled, may nevertheless be very mobile. As a consequence, the importance of traits that allow species to pass through 
the later filters of the invasion process may be obscured or diluted if one would take a random sample of all unsuccessful aliens.

While there is already empirical support for some of the predictions that we based on our schema of questions (e.g. the association of success with high environmental tolerance, high dispersibility and traits related to priority effects), others are not or infrequently supported. There are multiple possible reasons why studies may have failed to find associations between traits and success of alien species. One reason could be that the trait of interest is truly not important for success. However, there could also be many other reasons: (i) the contribution of a trait is obscured by extrinsic drivers of success, such as introduction frequency. (ii) The comparator group may have been inappropriate. Most studies on traits associated with invasiveness still use native species as noninvasive controls, although in many cases the traits of successful aliens should be similar to those of the natives (Table 1). A comparator problem could also arise when the successful aliens and the comparators belong to completely different taxonomic groups. Consequently, many studies have avoided this problem by making comparisons within specific families or corrected for it by applying a phylogenetic correction. (iii) As explained in the preceding paragraph and in Fig. 2, if one compares a successful alien to any nonsuccessful alien, the latter might already have failed at an earlier step for which the trait of interest was not relevant. (iv) There may be a nonlinear (e.g. unimodal) instead of a linear relation between trait values and success. (v) The spatial scale at or the context in which the trait should be important was not considered. (vi) Interactions among traits were not considered (see Küster et al. 2008 for a notable exception). Certain traits may only contribute to the success of an alien give the presence of another characteristic. Our schema of questions (Fig. 1) might help to understand such interactions. For example, environmental tolerance increases the likelihood that an appropriate environment is present (question A1) and time to germination whether it can quickly occupy a vacant niche (question B1). Then among all introduced alien plants, time to germination might only contribute to invasiveness for species that also have a wide environmental tolerance. (vii) There are trade-offs between potentially important traits (e.g. competitive ability and resistance against generalist herbivores) or between multiple functions of a single trait (e.g. seed size, as discussed above under question A2) that may also act across different invasion stages. Most of these issues can be avoided, and we hope that our schema of questions might contribute to this.

The Darwinian demon, that is a species that is superior in any trait and in all possible contexts, does not exist as a consequence of the above-mentioned tradeoffs (Law 1979). Therefore, it is unlikely to find a species that possesses all characteristics for being invasive in any context. Indeed, in an attempt by Williamson (1996) to test the importance of Baker's ideal-weed characteristics, he found that none of the 49 annual plant species that he had selected possessed more than seven of the 14 ideal-weed characteristics. Interestingly, however, it seems that many of the ideal-weed characteristics such as self-fertilization, clonal reproduction, fast growth and environmental tolerance (Levin 2002) come together in polyploid plants. Indeed, it has been reported that polyploid plants are more likely to be invasive than diploid ones (Pandit et al. 2011, 2014; te Beest et al. 2012). Nevertheless, although some polyploid plants may approach the Darwinian demon, it is still difficult to point out which characteristic of polyploids is driving their success.

Most of the studies that test for associations between traits and success of alien plants draw inferences based on large-scale geographical patterns or use a classification of aliens as non-naturalized, naturalized or invasive at those scales. While these studies provide important insights into traits that might be important for the questions that are relevant at the regional scale (questions A0 A2 in Fig. 1), they do not necessarily provide insight into the questions that are relevant at the community level (questions B0 B2 in Fig. 1). While it is possible to identify some introduced aliens that are not successful for a larger region, this is more difficult for a local community. There we know which alien species have established, but not which ones managed to get there and failed to establish. Controlled experimental introductions of novel species into native communities could provide important insights in which traits might be important for establishment in a specific community.

Several studies have performed such experimental introductions. However, most of them focussed on extrinsic factors, such as disturbance and species richness, rather than on intrinsic species traits (Robinson et al. 1995; Naeem et al. 2000; Seabloom et al. 2003; Maron et al. 2013). Moreover, most of these studies introduced only one or few species, which precludes comparisons of characteristics associated with establishment success. A notable exception is a study by Burke \& Grime (1996); they experimentally introduced 54 nonlocal, though native, species into a single limestone grassland in the UK. They found that particularly species with large seeds and fast and profuse germination under different temperature and light conditions were successful during the first 2 years of the study. In a later assessment of the same experiment, Thompson et al. (2001) reported that for the change in cover of the species during the subsequent 3 years, none of the 
tested traits had a significant effect. This, however, was after applying the very conservative Bonferroni correction (Moran 2003); without that correction, the positive effects of competitive ability and the negative effect of palatability would have been significant. More recently, Kempel et al. (2013) introduced 48 alien and 45 native plant species into eight disturbed (tilled) and eight nondisturbed grassland sites in Switzerland, and in parallel, experiments assessed functional traits of the species. They also found that the importance of the different traits changed over time, but that at the end of the 3year study, particularly native species and like in the study of Thompson et al. (2001) species with a high resistance against a generalist herbivore were successful. Moreover, perennial species were more successful, and this was particularly the case in the disturbed grassland plots, indicating context dependency. A limitation of these two multispecies introduction experiments is that that they did not consider how the introduced species differed from the native resident species. Fargione et al. (2003), however, did this, although only for a single characteristic, the functional guild. By introducing a total of 27 native and exotic species belonging to four different guilds C3 grasses, C4 grasses, legumes and nonlegume forbs into experimental grassland plots of different species richness, they showed that establishment of introduced species was inhibited by the presence of resident species from the same guild. So, multispecies experimental introductions might provide important insights into which characteristics are important for establishment in specific local communities.

\section{Conclusion}

In the 50 years after the publication of Baker's list of the ideal-weed characteristics in 1965, many studies have tested for traits associated with the success of alien plants. Although there is support for the importance of some of the characteristics listed by Baker (1965), such as fast growth, self-compatibility and high seed output, there also appear to be many exceptions or inconsistent results. In the face of the frequently emphasized context dependency, we should move away from the search for a 'one-size-fits-all' combination of traits that explains success. Instead, we might do better to focus on identifying the different syndromes of traits possessed by successful aliens when different sets of abiotic and biotic filters are imposed. Our schema of questions can help in organizing efforts to identify such syndromes of successful alien species by (i) acknowledging the importance of scale when asking questions about the success of alien species, moving from larger to smaller (community) scales as one progresses through the schema; (ii) sorting the traits that are most relevant to species success at each question; and (iii) identifying the best comparator groups. So, if we ask the right questions at the appropriate scale and use appropriate comparators, research on traits may tell us whether they are important or not.

\section{Acknowledgements}

We would like to thank the organizers of the The Baker and Stebbins Legacy Symposium for inviting us to write this study, and Rob Colautti, Keneth Whitney, Marcel Rejmánek and an anonymous reviewer for helpful comments on a previous ver sion. MvK and NM thank the DFG for funding (Grant KL $1866 / 51$ ). WD also thanks the DFG for funding (Grant DA 1502/1 1).

\section{References}

Ackerly DD, Cornwell WK (2007) A trait based approach to community assembly: partitioning of species trait values into within and among community components. Ecology Letters, 10, 135145.

Baker HG (1955) Self compatibility and establishment after 'long distance' dispersal. Evolution, 9, 347349.

Baker HG (1965) Characteristics and modes of origin of weeds. In: The Genetics of Colonizing Species (eds Baker HG, Stebbins GL), pp. 147 172. Academic Press, New York.

Baker HG (1974) The evolution of weeds. Annual Review of Ecology and Systematics, 5, 123.

te Beest M, Le Roux JJ, Richardson DM et al. (2012) The more the better? The role of polyploidy in facilitating plant inva sions. Annals of Botany, 109, 1945.

Belyea LR, Lancaster J (1999) Assembly rules within a contin gent ecology. Oikos, 86, 402416.

Bucharová A, van Kleunen M (2009) Introduction history and species characteristics partly explain naturalization success of North American woody species in Europe. Journal of Ecol ogy, 97, 230238.

Burke MJW, Grime JP (1996) An experimental study of plant community invasibility. Ecology, 77, 776790.

Caley P, Kuhnert PM (2006) Application and evaluation of classification trees for screening unwanted plants. Austral Ecology, 31, 647655.

Callaway RM, Aschehoug ET (2000) Invasive plants versus their new and old neighbors: a mechanism for exotic inva sion. Science, 290, 521523.

Castro Díez P, Godoy O, Saldana A, Richardson DM (2011) Predicting invasiveness of Australian acacias on the basis of their native climatic affinities, life history traits and human use. Diversity and Distributions, 17, 934945.

Chrobock T, Kempel A, Fischer M, van Kleunen M (2011) Introduction bias: cultivated plant species germinate faster and more profusely than native species in Switzerland. Basic and Applied Ecology, 12, 244250.

Cullen J, Knees SG, Cubey HS, eds (2011) The European Garden Flora. Cambridge University Press, Cambridge, UK.

Daehler CC, Denslow JS, Ansari S, Kuo H C (2004) A risk assessment system for screening out invasive pest plants from Hawaii and other Pacific islands. Conservation Biology, 18, 360368 
Darwin C (1859) The Origin of Species. John Murray, London.

Davidson AM, Jennions M, Nicotra AB (2011) Do invasive spe cies show higher phenotypic plasticity than native species and, if so, is it adaptive? A meta analysis. Ecology Letters, 14, 419431.

Daws MI, Hall J, Flynn S, Pritchard HW (2007) Do invasive species have bigger seeds? Evidence from intra and inter specific comparisons. South African Journal of Botany, 73, 138 143.

Dawson W, Burslem DFRP, Hulme PE (2009) Factors explain ing alien plant invasion success in a tropical ecosystem differ at each stage of invasion. Journal of Ecology, 97, 657665.

Dawson W, Fischer M, van Kleunen M (2012) Common and rare plant species respond differently to fertilisation and competition, whether they are alien or native. Ecology Letters, 15,873880

DeFalco LA, Bryla DR, Smith Longozo V, Nowak RS (2003) Are Mojave Desert annual species equal? Resource acquisi tion and allocation for the invasive grass Bromus madritensis subsp. rubens (Poaceae) and two native species. American Journal of Botany, 90, 10451053.

Dietz H, Edwards PJ (2006) Recognition that causal processes change during plant invasion helps explain conflicts in evi dence. Ecology, 87, 13591367.

Dostál P (2011) Plant competitive interactions and invasiveness: searching for the effects of phylogenetic relatedness and ori gin on competition intensity. American Naturalist, 177, 655 667.

Dostál P, Dawson W, van Kleunen M, Keser LH, Fischer M (2013) Central European plant species from more productive habitats are more invasive at a global scale. Global Ecology and Biogeography, 22, 6472.

Drenovsky RE, Martin CE, Falasco MR, James JJ (2008) Varia tion in resource acquisition and utilization traits between native and invasive perennial forbs. American Journal of Bot any, 95, 681687.

Fargione J, Brown CS, Tilman D (2003) Community assembly and invasion: an experimental test of neutral versus niche processes. Proceedings of the National Academy of Sciences, 100, 89168920

Funk JL (2013) The physiology of invasive plants in low resource environments. Conservation Physiology, 1, doi: 10. 1093/conphys/cot026.

Galloway JN, Townsend AR, Erisman JW et al. (2008) Transfor mation of the nitrogen cycle: recent trends, questions, and potential solutions. Science, 320, 889892.

Gioria M, Pyšek P, Moravcová L (2012) Soil seed banks in plant invasions: promoting species invasiveness and long term impact on plant community dynamics. Preslia, 84, 327 350.

Godoy O, Valladares F, Castro Díez P (2012) The relative importance for plant invasiveness of trait means, and their plasticity and integration in a multivariate framework. New Phytologist, 195, 912922.

Goeze E (1916) Liste der seit dem 16. Jahrhundert bis auf die Gegenwart in die Garten und Parks Europas eingefuhrten Baume und Straucher. Mitteilungen der Deutschen Dendrologis chen Gesellschaft, 25, 129201.

Gurevitch J, Fox GA, Wardle GM, Inderjit Taub D (2011) Emer gent insights from the synthesis of conceptual frameworks for biological invasions. Ecology Letters, 14, 407418.
Hamilton MA, Murray BR, Cadotte MW et al. (2005) Life his tory correlates of plant invasiveness at regional and conti nental scales. Ecology Letters, 8, 10661074.

Hao JH, Qiang S, Chrobock T, van Kleunen M, Liu QQ (2011) A test of Baker's Law: breeding systems of invasive species of Asteraceae in China. Biological Invasions, 13, 571580.

Heywood VH, Sharrock S (2013) European Code of Conduct for Botanic Gardens on Invasive Alien Species. Council of Europe, Strasbourg, Botanic Gardens Conservation International, Richmond.

Hulme PE, Bacher S, Kenis M et al. (2008) Grasping at the routes of biological invasions: a framework for integrating pathways into policy. Journal of Applied Ecology, 45, 403414.

Kempel A, Chrobock T, Fischer M, Rohr RP, van Kleunen M (2013) Determinants of plant establishment success in a mul tispecies introduction experiment with native and alien spe cies. Proceedings of the National Academy of Sciences, 110, 1272712732.

van Kleunen M, Fischer M (2005) Constraints on the evolution of adaptive phenotypic plasticity in plants. New Phytologist, 166, 4960.

van Kleunen M, Johnson SD (2007a) South African Iridaceae with rapid and profuse seedling emergence are more likely to become naturalized in other regions. Journal of Ecology, 95 , 674681.

van Kleunen M, Johnson SD (2007b) Effects of self compatibil ity on the distribution range of invasive European plants in North America. Conservation Biology, 21, 15371544.

van Kleunen M, Johnson SD, Fischer M (2007) Predicting natu ralization of southern African Iridaceae in other regions. Journal of Applied Ecology, 44, 594603.

van Kleunen M, Manning JC, Pasqualetto V, Johnson SD (2008) Phylogenetically independent associations between autono mous self fertilization and plant invasiveness. American Natu ralist, 171, 195201.

van Kleunen M, Weber E, Fischer M (2010a) A meta analysis of trait differences between invasive and non invasive plant species. Ecology Letters, 13, 235245.

van Kleunen M, Dawson W, Schlaepfer DR, Jeschke JM, Fi scher M (2010b) Are invaders different? A conceptual frame work of comparative approaches for assessing determinants of invasiveness. Ecology Letters, 13, 947958.

van Kleunen M, Dawson W, Bossdorf O, Fischer M (2014) The more the merrier: multi species experiments in ecology. Basic and Applied Ecology, 15, 19.

Knapp S, Kuhn I (2012) Origin matters: widely distributed native and non native species benefit from different func tional traits. Ecology Letters, 15, 696703.

Kolar CS, Lodge DM (2001) Progress in invasion biology: pre dicting invaders. Trends in Ecology and Evolution, 16, 199204.

Kueffer C, Pyšek P, Richardson DM (2014) Integrative invasion science: model systems, multi site studies, focused meta analysis and invasion syndromes. New Phytologist, 200, 615 633.

Kuster EC, Kuhn I, Bruelheide H, Klotz S (2008) Trait interac tions help explain plant invasion success in the German flora. Journal of Ecology, 96, 860868.

Lake JC, Leishman MR (2004) Invasion success of exotic plants in natural ecosystems: the role of disturbance, plant attri butes and freedom from herbivores. Biological Conservation, 117, 215226. 
Law R (1979) Optimal life histories under age specific preda tion. American Naturalist, 114, 399417.

Leung B, Roura Pascual N, Bacher S et al. (2012) TEASIng apart alien species risk assessments: a framework for best prac tices. Ecology Letters, 15, 14751493.

Levin D (2002) The Role of Chromosomal Change in Plant Evolu tion. Oxford University Press, New York.

Lonsdale WM (1994) Inviting trouble: introduced pasture spe cies in northern Australia. Australian Journal of Ecology, 19, 345354.

Maron JL, Waller LP, Hahn MA et al. (2013) Effects of soil fungi, disturbance and propagule pressure on exotic plant recruitment and establishment at home and abroad. Journal of Ecology, 101, 924932.

Moles AT, Westoby M (2006) Seed size and plant strategy across the whole life cycle. Oikos, 113, 91105.

Moles AT, Flores Moreno H, Bonser SP et al. (2012) Invasions: the trail behind, the path ahead, and a test of a disturbing idea. Journal of Ecology, 100, 116127.

Moodley D, Geerts S, Richardson DM, Wilson JRU (2013) Dif ferent traits determine introduction, naturalization and inva sion success in woody plants: Proteaceae as a test case. PLoS One, 8, e75078.

Moran MD (2003) Arguments for rejecting the sequential Bon ferroni in ecological studies. Oikos, 100, 403405.

Moravcová L, Pyšek P, Jarošik V, Havlíčková V, Zákravský P (2010) Reproductive characteristics of neophytes in the Czech Republic: traits of invasive and non invasive species. Preslia, 82, 365390.

Morin PJ (1999) Community Ecology. Wiley Blackwell, Malden, Massachusetts.

Murray BR, Phillips ML (2010) Investment in seed dispersal structures is linked to invasiveness in exotic plant species of south eastern Australia. Biological Invasions, 12, 22652275.

Muth NJ, Pigliucci M (2006) Traits of invasives reconsidered: phenotypic comparisons of introduced invasive and intro duced noninvasive plant species within two closely related clades. American Journal of Botany, 93, 188196.

Naeem S, Knops JMH, Tilman D, Howe KM, Kennedy T, Gale S (2000) Plant diversity increases resistance to inva sion in the absence of covarying extrinsic factors. Oikos, 91, 97108 .

Nathan R (2006) Long distance dispersal of plants. Science, 313, 786788 .

Nathan R, Schurr FM, Spiegel O, Steinitz O, Trakhtenbrot A, Tsoar A (2008) Mechanisms of long distance seed dispersal. Trends in Ecology and Evolution, 23, 638647.

Palacio López K, Gianoli E (2011) Invasive plants do not dis play greater phenotypic plasticity than their native or non invasive counterparts: a meta analysis. Oikos, 120, 13931401.

Pandit MK, Pocock MJ, Kunin WE (2011) Ploidy influences rar ity and invasiveness in plants. Journal of Ecology, 99, 1108 1115.

Pandit MK, White SM, Pocock MJ (2014) The contrasting effects of genome size, chromosome number and ploidy level on plant invasiveness: a global analysis. New Phytologist, 203, 697703.

Penuelas J, Sardans J, Llusia J et al. (2010) Faster returns on 'leaf economics' and different biogeochemical niche in inva sive compared with native plant species. Global Change Biol ogy, 16, 21712185.
Petitpierre B, Kueffer C, Broennimann O, Randin C, Daehler C, Guisan A (2012) Climatic niche shifts are rare among terres trial plant invaders. Science, 335, 13441348.

Prati D, Bossdorf O (2004) Allelopathic inhibition of germina tion by Alliaria petiolata (Brassicaceae). American Journal of Botany, 91, 285288.

Pyšek P, Richardson DM (2007) Traits associated with invasive ness in alien plants: where do we stand? In: Biological Inva sions (ed. Nentwig W), pp. 97 125. Springer, New York.

Pyšek P, Richardson DM, Williamson M (2004) Predicting and explaining plant invasions through analysis of source area floras: some critical considerations. Diversity and Distribu tions, 10, 179187.

Pyšek P, Jarošik V, Pergl J et al. (2009) The global invasion suc cess of Central European plants is related to distribution characteristics in their native range and species traits. Diver sity and Distributions, 15, 891903.

Pyšek P, Manceur AM, Alba C et al. (2014) Naturalization of central European plants in North America: species traits, habitats, propagule pressure, residence time. Ecology, doi: org/10.1890/14 1005.1.

Rambuda TD, Johnson SD (2004) Breeding systems of invasive alien plants in South Africa: does Baker's rule apply? Diver sity and Distributions, 10, 409416.

Reichard SH, Hamilton CW (1997) Predicting invasions of woody plants introduced into North America. Conservation Biology, 11, 193203.

Rejmánek M (1999) Invasive plant species and invasible ecosys tems. In: Invasive Species and Biodiversity Management (eds Sandlund OT, Schei PJ, Viken Å), pp. 79 102. Kluwer Aca demic Publishers, Dordrecht, the Netherlands.

Rejmánek M, Richardson DM (1996) What attributes make some plants species more invasive? Ecology, 77, 16551661.

Rejmánek M, Richardson DM, Pyšek P (2013) Plant invasions and invisibility of plant communities. In: Vegetation Ecology, 2nd edn (eds van der Maarel E, Franklin J), pp. 332355. John Wiley \& Sons, Chichester, UK.

Richardson DM, Pyšek P, Rejmánek M, Barbour MG, Panetta FD, West CJ (2000) Naturalization and invasion of alien plants: concepts and definitions. Diversity and Distributions, 6, 93107.

Robinson GR, Quinn JF, Stanton ML (1995) Invasibility of experimental habitat islands in a California winter annual grassland. Ecology, 76, 786794.

Seabloom EW, Harpole WS, Reichman OJ, Tilman D (2003) Invasion, competitive dominance, and resource use by exotic and native California grassland species. Proceedings of the National Academy of Sciences, 100, 1338413389.

Shea K, Chesson P (2002) Community ecology theory as a framework for biological invasions. Trends in Ecology and Evolution, 17, 170176.

Speek TAA, Plotz LAP, Ozinga WA, Tamis WLM, Schaminée JHJ, van der Putten WH (2011) Factors relating to regional and local success of exotic plant species in their new range. Diversity and Distributions, 17, 542551.

Stinson K, Campbell SA, Powell JR et al. (2006) Invasive plant suppresses the growth of native Tree seedlings by disrupting belowground mutualisms. PloS Biology, 4, 727 731, e140.

Theoharides KA, Dukes JS (2006) Plant invasion across space and time: factors affecting nonindigenous species success during four stages of invasion. New Phytologist, 176, 256273. 
Thompson K, Davis MA (2011) Why research on traits of inva sive plants tells us very little. Trends in Ecology and Evolution, 26, 155156.

Thompson K, Hodgson JG, Grime JP, Burke MJW (2001) Plant traits and temporal scale: evidence from a 5 year invasion experiment using native species. Journal of Ecology, 89, 1054 1060.

Turnbull LA, Paul Victor C, Schmid B, Purves DW (2008) Growth rates, seed size, and physiology: do small seeded species really grow faster? Ecology, 89, 13521363.

Vilà M, Weiner J (2004) Are invasive plant species better com petitors than native plant species? evidence from pair wise experiments. Oikos, 105, 229238.

Widrlechner MP, Thompson JR, Iles JK, Dixon PM (2004) Mod els for predicting the risk of naturalization of non native woody plants in Iowa. Journal of Environmental Horticulture, 22, 2331 .
Williamson M (1996) Biological Invasions. Chapman \& Hall, London, UK.

Wilsey BJ, Barber K, Martin LM (2014) Exotic grassland species have stronger priority effects than natives regardless of whether they are cultivated or wild genotypes. New Phytolo gist, doi: $10.1111 / \mathrm{nph} .13028$.

Young JA, Evans RA (1976) Responses of weed populations to human manipulations of the natural environment. Weed Sci ence, 24, 186190

M.v.K. conceived the idea for this study and lead the writing. W.D. and N.M. contributed ideas and examples and contributed to the writing. 